\title{
Intelligent System for College English Listening and Writing Training
}

\author{
https://doi.org/10.3991/ijet.v13i10.9457 \\ Cui Li \\ Jilin Institute of Chemical Technology, Jilin, China \\ licui26@126.com
}

\begin{abstract}
This paper builds on the requirements of listening and writing, conducts a detailed analysis on demands and a feasibility study, and designs a set of intelligent English listening and writing training system. This system carries out an analysis on demands from three main aspects - the orchestration system before the test, the mock test subsystem during the test and the achievement management system after the test, and describes the functions of the college English listening and speaking simulation test system. After technical analysis, the nonfunctional requirements of the system are introduced. The design of the system makes a hierarchical description of the system's overall architecture, achievement management architecture and sorchestration system architecture, and demonstrates database design, design and interface design of this system. The test demonstrates favorable results and this system meet the functional requirements.
\end{abstract}

Keywords—achievement management; English writing system; online education; test simulation

\section{Introduction}

With the rapid development of computer technology and the tremendous development of the campus network, various types of English proficiency tests have widely applied computer technology. Foreign researchers have adopted computer systems to score the pronunciation of the speaking English examinees [1]. Domestic college English education is also actively developing a web-based English test system [2]. English listening and speaking is an indispensable part of English teaching, and also an essential approach to obtain language information and language feelings. As far as college English education is concerned, over the years, listening tests are listed at the first place of the paper with an increasingly large proportion. Listening and writing trainings are attached with greater significance [3].

In the 21st century, China's English curriculum aims to cultivate students' ability of comprehensive English application and to fully improve their English communication competence. The realization of these goals are mainly dependent on the construction of a scientific, systematic and complete English education system from basic education to higher education. The addition of listening and speaking exams is one of the effective 
measures to construct this system, which is of great advantage to establish a complete education system, and of full necessity to cultivate a generalist who adapts to the rapid development of the economic society. It is of strategic significance to meet the needs of the society for high-quality talents [4]. Automated exams for English listening and speaking have been conducted in the form of man-machine dialogue. Previously, the non-integrated version of the English listening and speaking mock test system separates the exam and the score. This system is flawed in the situation of teachers' application and its inability to derive student scores in real time [5]. The previous market research has found that most of the mold test systems are recording tool systems, which can only be used to have a detailed knowledge about the examination process. However, it cannot generate scores, greatly undermining the system's abilities to evaluate the student level and guide targeted teaching. Although some individual versions of the software already have an automatic scoring function, but technically yet to be further improved [6]. As a means of measuring the degree of the mastery of spoken language, the addition of listening and speaking exams can play a decisive role in detecting the language knowledge of the students and their ability to apply it in the communication, which has positive significance to improve the validity of English test and incalculable effects on promoting students' free communication [7]. Secondly, from the perspective of test science, a scientific and comprehensive language test should include speaking examinations. The addition of listening and speaking exams can more fully reflect the students' language proficiency at different levels and the accuracy, fluency and appropriateness of the language in the process of verbal communication, thereby enhancing the validity of the examination [8]. English education plays a crucial role in the entire education system, and English listening and speaking test is an essential part of English exams which is used to measure the students' English listening and speaking competence in a comprehensive and accurate way [9].

In light of the above problems, the paper builds on service education, combines the core technology of intelligent speech, and puts forward the solution to college English listening and speaking simulation tests - the design and the development of a simulation test system for college English listening and speaking. The test process and the scoring engine that are consistent with the formal test are designed to help schools to organize intelligent and fully automated English listening and speaking tests at any time and to have a convenient and quick understanding of students' listening and speaking ability level. This system provides students with an independent humancomputer interactive learning environment, real daily trainings and a pre-test simulation platform and it plays a critical part in improving the English capacities of the students.

\section{System Design}

\subsection{System architecture}

The overall system architecture is illustrated by figure 1 . The front UI interface is displayed as three module entries by means of WPF design. The implementation of UI operations requires the support of the BLL business logic layer. DAL data access layer 
and the operation layer of the database provide data services for the business logic layer or the presentation layer. Because UI calls DAL and DAL calls BLL, the public class and the utility are connected to the database and the underlying method of basic operations, including add, delete, modify and search, is performed [10]. In addition, the public class and the entity layer map data table and Common.

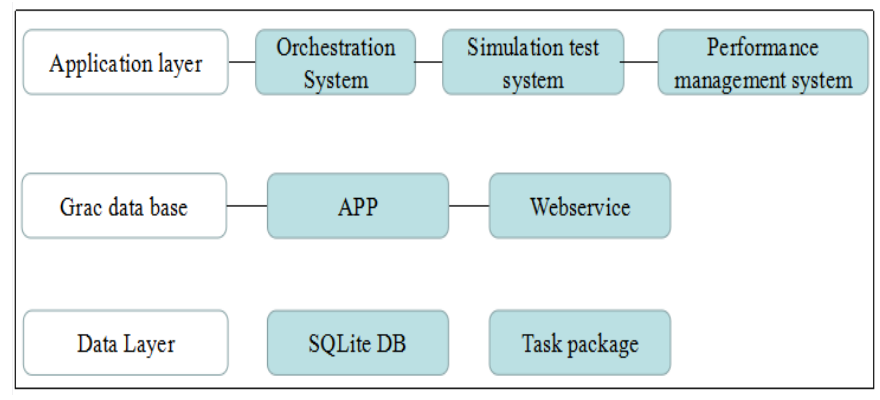

Fig. 1. System architecture diagram

The layout of orchestration system architecture is shown in Figure 2. Like the overall system architecture, a three-tier architecture model is applied, and the client UI employs the manifestation of WPF. The data layer includes APP coordination and SQLite database. The document library contains paper resources and task packages. In the system, a task package corresponds to a test paper in principle. Public library, Log and Common, serve as the debugger and the important and indispensable means to monitor the program run [11].

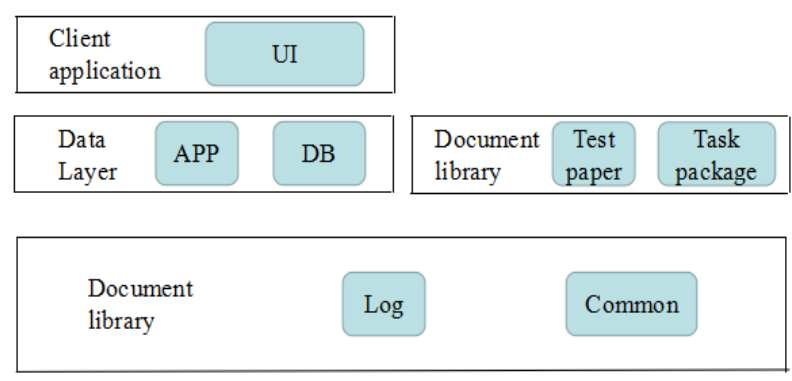

Fig. 2. Layout of system architecture

Achievement management framework is demonstrated in Figure 3, which also applies a three-tier architecture model. In the external request processing and external services, WEB Handler is employed to define the properties and the compiler options of the HTTP processing program (.ashx) file. Client UI adopts WPF presentation. The data layer includes APP coordination and AQLite database [12]. Public library are Log and Common. UI requests services through the WEB Handler, and WEB Handler calls the relevant data from the background and then returns it to UI. 
Figure 4 is the physical topological diagram of the simulation test system which is divided into examination management, invigilator (examination machine) and award paper.

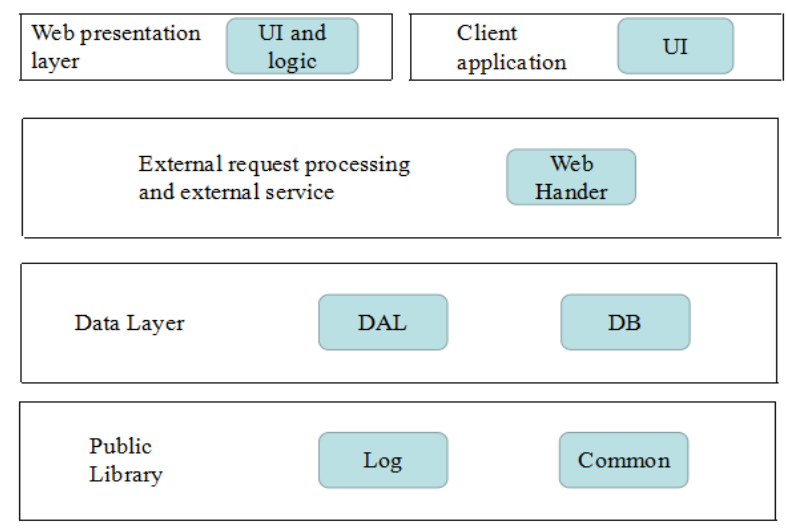

Fig. 3. Achievement management framework

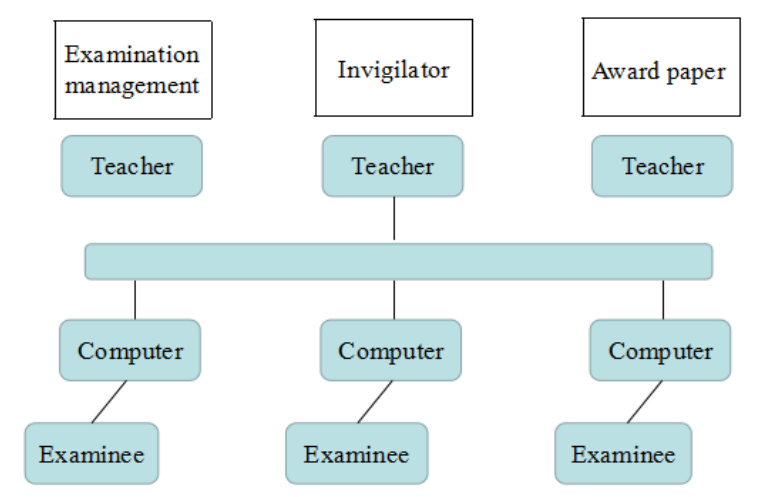

Fig. 4. Simulation test system architecture - Physical Topology

\subsection{A detailed design of data sheet}

The details of each database table are indicated as follows.

As illustrated, Exam paper contains the ID, number, and name fields of the paper, and paperId is the primary key.

The record of exam paper tasks is illustrated in the table, including the ID of the test paper record, the ID of the paper and the ID of the task, where PaperRecordId is the primary key [13]. 
Table 1. Exam paper

\begin{tabular}{|c|l|l|l|l|}
\hline Key & \multicolumn{1}{|c|}{ Name } & \multicolumn{1}{c|}{ DateType } & \multicolumn{1}{c|}{ Notnull } & \multicolumn{1}{c|}{ Description } \\
\hline Print key & PaperId & Integer & Notnull & Test paper ID \\
\hline & PaperNo & NVaChar[100] & & Paper number \\
\hline & PaperName & NVaChar[100] & Notnull & Test name \\
\hline & Reserved & & & Reserved field 1 \\
\hline
\end{tabular}

Table 2. Record of examination PaperRecord

\begin{tabular}{|c|l|l|l|l|}
\hline Key & \multicolumn{1}{|c|}{ Name } & \multicolumn{1}{|c|}{ DateType } & \multicolumn{1}{c|}{ Notnull } & \multicolumn{1}{c|}{ Description } \\
\hline Print key & PaperId & Integer & Notnull & Examination paper record ID \\
\hline & PaperNo & NVaChar[100] & & Paper ID \\
\hline & PaperName & NVaChar[100] & Notnull & Task ID \\
\hline
\end{tabular}

\subsection{Web design.}

The design of history page. The information about history task record page is demonstrated in Table 3, which is used to display the history task list and support conditional search. The required APP coordinations include GetAllTask() that gets the history tasks, GetSearchList() that gets task name and class name and dynamically generates search conditions, and GetSearchTask() that gets the task information based on condition search [14].

Table 3. History page information table

\begin{tabular}{|l|l|l|l|l|}
\hline Name & $\begin{array}{c}\text { Page de- } \\
\text { scription }\end{array}$ & \multicolumn{1}{|c|}{$\begin{array}{c}\text { Function } \\
\text { point }\end{array}$} & Page implementation & \multicolumn{1}{c|}{ APP coordination } \\
\hline \multirow{2}{*}{$\begin{array}{l}\text { History } \\
\text { Task.html }\end{array}$} & $\begin{array}{l}\text { Show history } \\
\text { task list, sup- } \\
\text { port condi- } \\
\text { tion search } \\
\text { tory task in- } \\
\text { formation dis- } \\
\text { play }\end{array}$ & $\begin{array}{l}\text { Show all historical } \\
\text { tasks by default }\end{array}$ & $\begin{array}{l}\text { GetAllTask()Get historical } \\
\text { tasks }\end{array}$ \\
\cline { 3 - 5 } & $\begin{array}{l}\text { Historical } \\
\text { Quest }\end{array}$ & $\begin{array}{l}\text { Support task name, } \\
\text { class name, date search } \\
\text { to display the corre- } \\
\text { sponding task infor- } \\
\text { mation }\end{array}$ & $\begin{array}{l}\text { GetSearchList()Get task } \\
\text { name and class name, dynam- } \\
\text { ically generate search condi- } \\
\text { tions } \\
\text { GetSearchTask()Gets the task } \\
\text { information searched by the } \\
\text { condition }\end{array}$ \\
\hline
\end{tabular}

The design of achievement information list page. The information about the result information list page is indicated in Table 4. A few required APP coordinations are involved, which mainly are GetTaskDetaiIInfo() that gets the basic information of the 
current task, GetStudentExamInfo() that gets the statistics information of the current task, ExportStatiscalInfo() that gets student information of the current task and exports the statistics, ExportStudentsScoreList() that exports the student achievement table, and GetTaskDetaiIInfo() that gets the details about the historical tasks [15].

Table 4. List of information

\begin{tabular}{|c|c|c|c|c|}
\hline Name & $\begin{array}{l}\text { Page de- } \\
\text { scription }\end{array}$ & Function point & Page implementation & APP coordination \\
\hline \multirow{6}{*}{ Taskinfo.html } & \multirow{6}{*}{$\begin{array}{l}\text { Gets the } \\
\text { task infor- } \\
\text { mation } \\
\text { searched by } \\
\text { the condi- } \\
\text { tion }\end{array}$} & $\begin{array}{l}\text { Current task in- } \\
\text { formation }\end{array}$ & $\begin{array}{l}\text { Display basic infor- } \\
\text { mation }\end{array}$ & Get the current task \\
\hline & & $\begin{array}{l}\text { Examination re- } \\
\text { sult distribution }\end{array}$ & $\begin{array}{l}\text { Use data to display the } \\
\text { page }\end{array}$ & Get current task statistics \\
\hline & & $\begin{array}{l}\text { List of test re- } \\
\text { sults }\end{array}$ & $\begin{array}{l}\text { Use the form to show } \\
\text { the candidate infor- } \\
\text { mation }\end{array}$ & $\begin{array}{l}\text { Get student information } \\
\text { for the current task }\end{array}$ \\
\hline & & Export statistics & $\begin{array}{l}\text { Derived results distri- } \\
\text { bution }\end{array}$ & Export statistics \\
\hline & & Export table & $\begin{array}{l}\text { Test results are ex- } \\
\text { ported to Excel }\end{array}$ & Export table \\
\hline & & Class search & Search by class & $\begin{array}{l}\text { Get detailed information } \\
\text { about the historical task }\end{array}$ \\
\hline
\end{tabular}

The design of evaluation test page. Table 5 indicates the evaluation test page information. Ajax is applied to generate test papers, and each question is marked with the correct rate, the original listening materials, demonstration listening materials and the examinees' recordings, as well as the individual reports [16]. The required APP coordinations mainly involve GetAnalysisPaper() that gets the information of the test paper to generate the test papers and gets the demo audio path, GetStudentPaperDetail() that gets student records, and ExportAnalysis() that exports papers.

Table 5. Evaluation test page information table

\begin{tabular}{|c|l|l|l|l|}
\hline Name & Page description & Function point & Page implementation & APP coordination \\
\hline & & Generate test pa- & $\begin{array}{l}\text { According to the infor- } \\
\text { mation returned by } \\
\text { Ajax, the correspond- } \\
\text { ing test paper }\end{array}$ & $\begin{array}{l}\text { Get the infor- } \\
\text { mation of the test } \\
\text { paper to generate } \\
\text { the test paper and } \\
\text { get the audio path }\end{array}$ \\
\cline { 3 - 5 } $\begin{array}{l}\text { Analysis } \\
\text { Pa- } \\
\text { per.html }\end{array}$ & $\begin{array}{l}\text { Generate task papers, } \\
\text { marking the correct rate } \\
\text { of each question, to fa- } \\
\text { cilitate teacher evalua- } \\
\text { tion }\end{array}$ & Play recording & $\begin{array}{l}\text { Pop up candidates re- } \\
\text { cording list, click to } \\
\text { play }\end{array}$ & Get student record \\
\cline { 3 - 6 } & & Export Report & $\begin{array}{l}\text { Will save it to local pa- } \\
\text { pers }\end{array}$ & Export papers \\
\hline
\end{tabular}




\subsection{The design of the main APP interface}

The design of the main UTExamApp interface is as follows:

1. Interface name: Function description of StudentDataChange: Transfer the student's exam results into data in the scoring system and insert it into the database. Parameter of return value: int.

2. Interface name: DeployData: Functional description: Obtain student achievement data from Task.db3 and analyze paper.schema for data conversion. Parameter of return value: void.

The design of the main ExamApp interface is as follows:

1. Interface name: GetAllTask: Function Description: Obtain a list of historical tasks, Parameter of return value: List ListAllTask

2. Interface name: GetSearchList: Function Description: Get the class name and task name and dynamically generate the search conditions, Parameter of return value: List ListClass

3. Interface name: GetSearchTask: Function Description: Get the task information based on condition search, Parameter of return value: List ListInfo

4. Interface name: GetTaskDetailInfo: Function Description: Get the current task information, Parameter of return value: Exam TaskInfo

\section{System Implementation and Test Run}

\subsection{The composition of form module of main interface}

The main interface of the system is illustrated in Figure 5. The main interface is initiated. Three modules are accessible on the main interface: examination management module, simulation test module and evaluation test paper module. The main interface, including the interface applied in the latter section, is produced by means of WPF technology.

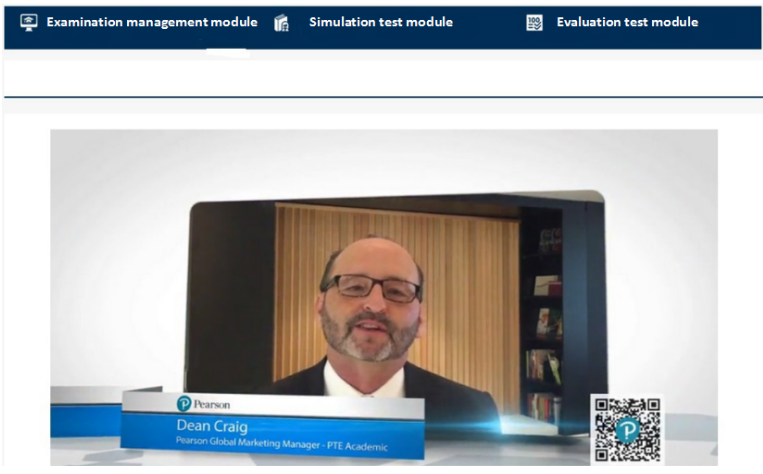

Fig. 5. Main interface Elpsim_SchoolStart 


\subsection{The implementation of the examination management module}

Introduction to the examination management process. Enter the examination management module and establish a new test task. The task name can be modified before the task is generated. When the new task is established, the files required in the task package should be added in the task package.

The function of task modification and delete can only modify the task name and other basic information and it cannot handle student information that is in operation.

Add student information, download templates, and add student information in bulk.

Select the test paper.

Generate a task.

Implementation of examination management. The examination management module is indicated in Figure 6. A new task is created in the examination management interface for examination. In the process of creating a task, the basic information of the task is included, the student information file is entered and the exam paper is selected.

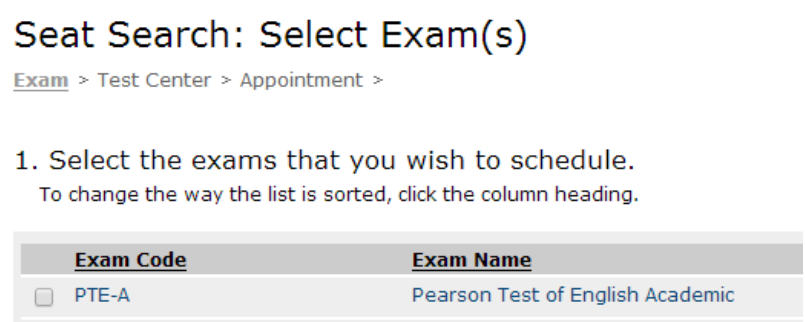

Fig. 6. Examination management module

\subsection{Introduction to the simulation test module}

The functions of the invigilator are as follows:

Log in to the invigilator. The task package information generated in the orchestration system can be automatically associated.

Issue a command of preparing to start the exam. The login situation of the examinees can be checked.

Issue a command of automatic audition. The recording situation of the examinees can be checked.

Issue a command of formal examination. The examination process of the examinees can be checked.

End the exam and acquire all the recordings of all the examinees.

Compatibility of question types.

Configure the individual student report. Whether the examinees can view the report after the test can be dynamically controlled.

Add the channel for viewing the scores.

The functions of the examination machine are as follows:

Automatically detect and install the client side by downloading it. 
Examinees sign in. Accept the command of exam preparation and log on the examination machine.

Start voice test. Automatically begin voice test after receiving the command of voice test.

Begin the formal examination session. Start answering the exam papers according to the exam instructions.

Compatibility of question types.

End the exam. After the examination, the answer and the recordings are automatically submitted. The invigilator is opened to view the report status.

After the exam, the individual achievement report can be viewed.

The simulation test platform, UT platform, includes the invigilator and the examination machine, as illustrated in Figure 7 and Figure 8.

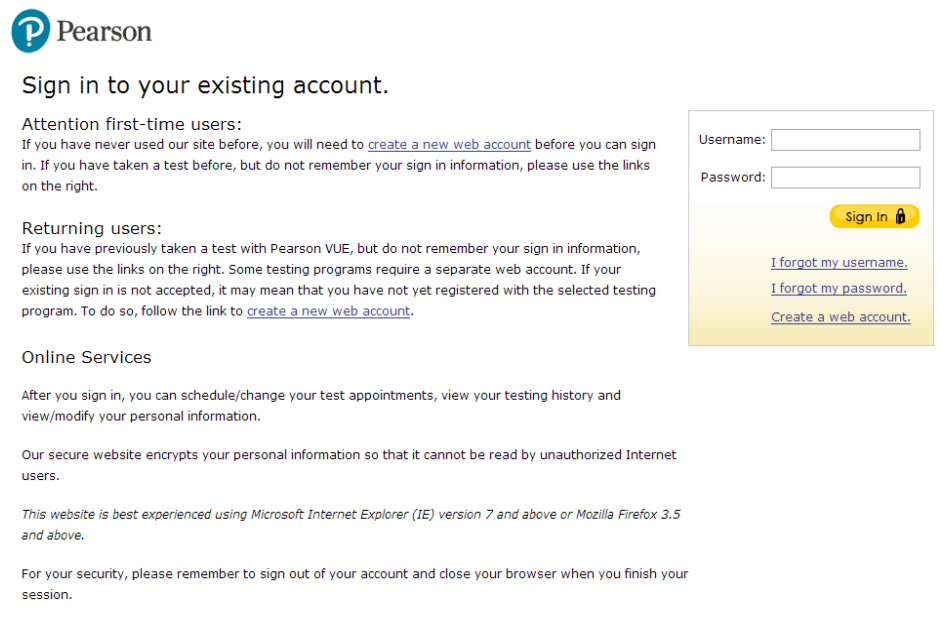

Fig. 7. Invigilator

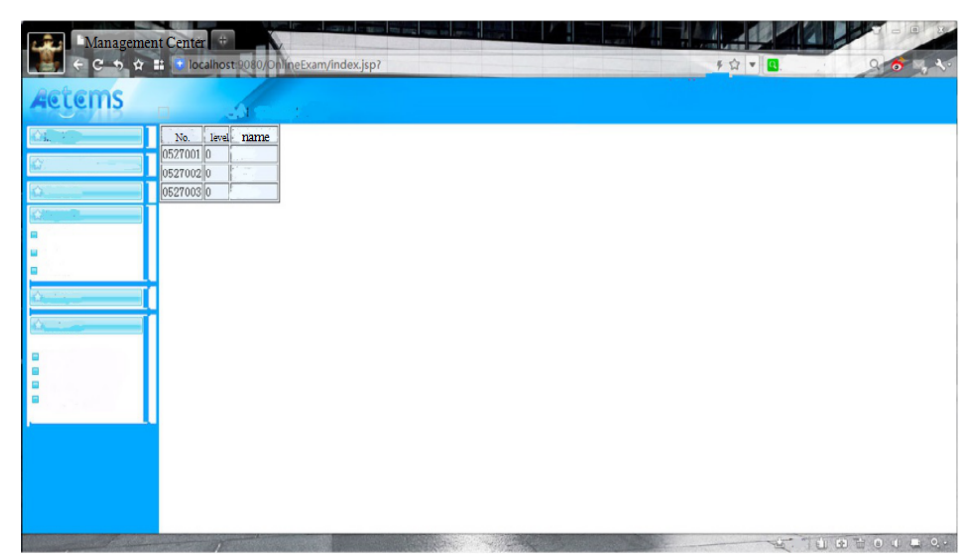

Fig. 8. Examination machine 


\subsection{The implementation of the evaluation test paper module}

(1) Introduction to the functions of the evaluation test paper View the task of history exam.

1. Statistical information of exam results.

1) Record the basic test information of this task, such as the total number of persons, real test, missing test and so on.

2) Build on the detailed list of examinees of this task.

2. A detailed report on student achievement.

View the detailed test results of a student.

3. Print the statistics.

Print the page information of the current exam task.

4. Derive the statistics.

Derive the page information of the current exam task with the representation of the form.

5. Derive the student grade table.

Derive the students' test results and enter the section of test papers.

(2) Implementation of the evaluation test paper

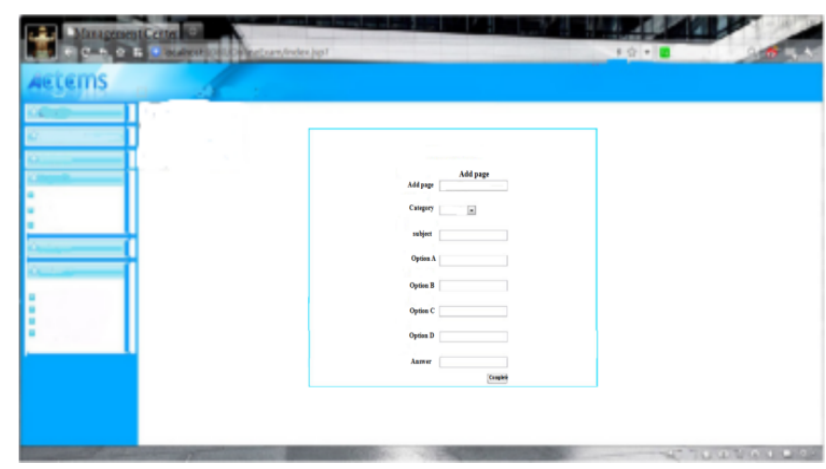

Fig. 9. Evaluation test module

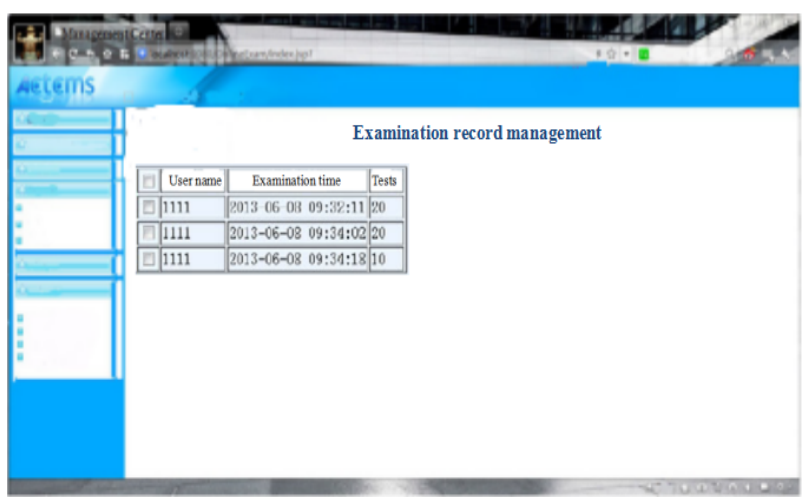

Fig. 10.Statistical analysis of results 
(1) View the interface of the history test task

Enter the evaluation test paper module and display the history of all the tasks, as indicated in Figure 9.

(2) View the interface of examination achievement analysis

The page of examination achievement analysis is demonstrated in Figure 10. The interface of GetExamTaskScoreInfo() is applied to view the examinee's achievement list.

\subsection{System testing and running}

The main purpose of system testing is to conduct a most comprehensive test on the software system so that this system project can meet the product demands and conform to the overall and detailed system design. The current software system testing is a critical step in ensuring software quality, final review of software specification, design and coding, as well as a scientific answer to the smooth development of the project.

1. Unit testing. Interfaces especially require unit testing. Otherwise, as a consequence, the module that requires data obtains incorrect data, which may lead to unimaginable errors or even system crashes and other issues.

2. Integration testing. In most cases, the findings in this testing step are errors in the general design.

3. System testing. The errors in this step are often found in demand specification. In the case of a perfect systematic function, the project needs to be managed. Problems are located in system testing to improve the system requirements. Eventually, the system achieves the desired goal.

\section{Conclusions}

1. The English listening and speaking simulation test system designed in this paper has added the pre-test orchestration subsystem, combined with the achievement management subsystem of the non-integrated version of English listening and speaking simulation test system, and formed a complete simulation test system comprising pre-test, in-the-test and post-test. This system is featured with the function of automatic scoring and statistical analysis and a fairly simple architecture with the application of $\mathrm{C} / \mathrm{S}$ architecture. The interface of each module applies WPF, and the UI performance illustrates more excellence.

2. The part of statistics is implemented by applying the embedded browser to open the page of the server side. Besides, Ajax technology, JSON data exchange format and JavaScript Highcharts are employed for the presentation. It is compatible with all the current major browsers with a faster loading speed and better performance effects. Data storage applies the lightweight SQLite database, and the deployment is more flexible and convenient. The evaluation engine employs the latest SEE42 integrated engine.

3. The paper has carried out a detailed analysis on demands and a feasibility study on the system design, focused on an analysis on demands from three main aspects: the 
orchestration system prior to the test, the simulated examination sub-system during the test and the achievement management system after the test, and made a use case description on the functions of the college English listening and speaking simulation test system. After the technical analysis, the system's non-functional requirements are introduced.

\section{$5 \quad$ References}

[1] P Ra, J., \& Rhee, K. J. (2018). Detection of gender related DIF in the Foreign Language Classroom Anxiety Scale. Educational Sciences: Theory \& Practice, 18(1), 47-60. https://doi.org/10.12738/estp.2018.1.0606

[2] Liu, N. (2013). Ipad infuse creativity in solid geometry teaching, Turkish Online Journal of Educational Technology, 12(2): 177-192.

[3] Lemke, J.L. (2010). Letramento metamidiático: transformando significadose mídias metamedia literacy: transforming meanings and media, Trabalhos Em Lingüística Aplicada, 49(2): 455-479. https://doi.org/10.1590/S0103-18132010000200009

[4] Meyers, E.M., Erickson, I., Small, R.V. (2013). Digital literacy and informal learning environments: an introduction, Learning, Media and Technology, 38(4): 355-367. https://doi.org/10.1080/17439884.2013.783597

[5] Kearney, M., Burden, K., Rai, T. (2015). Investigating teachers' adoption of signature mobile pedagogies, Computers \& Education, 80): 48-57.

[6] Hunt, P., McDonnell, J., Crockett, M.A. (2012). Reconciling an ecological curricular framework focusing on quality of life outcomes with the development and instruction of standards-based academic goals. Research and Practice for Persons with Severe Dis-abilities, 37(3): 139-152. https://doi.org/10.2511/027494812804153471

[7] Samilski, J.A.E., Lau, T.T.Y., Elbe, D.H.T., Aulakh, A.K., Lun, E.M.C. (2012). Drug use evaluation of moxifloxacin (avelox) using a hand-held electronic device at a Canadian teaching hospital. P\&T, 37(5): 291-299.

[8] Boyd, L.E., Ringland, K.E., Haimson, O.L., Fernandez, H., Bistarkey, M., Hayes, G.R. (2015). Evaluating a collaborative ipad game's impact on social relationships for children with autism spectrum disorder. ACM Transactions on Accessible Compu-ting, 7(1): 1-18. https://doi.org/10.1145/2751564

[9] Kaliaperumal, K.S.D.C. (2015). Incorporation of web-based applications and online resources in undergraduate medical education in the Irish republic. Can new changes be incorporated in the current medical curriculum. Journal of Natural Science Biology \& Medicine, 5(2): 445-9. https://doi.org/10.4103/0976-9668.136237

[10] Miranda, F.D.S.S. (2014). Integration of digital information technologies and commu-nication in learning contexts: analysis of three different moments of a teacher devel-opment course. Trab. Linguist. Apl, 53(1): 55-77. https://doi.org/10.1590/S0103-181320 $\underline{14000100004}$

[11] Vitalle, M.S.D.S., Almeida, R.G.D., Silva F.C.D. (2010). Training in adolescent health care: teaching experience. Revista Brasileira De Educação Médica, 34(34): 459-468. https://doi.org/10.1590/S0100-55022010000300017

[12] Engin, M., Donanci, S. (2015). Dialogic teaching and ipads in the EAP classroom, Computers \& Education, 88(C): 268-279. https://doi.org/10.1016/j.compedu.2015.06.005

[13] Smith, L. (2014). ICT for English in English ite: an investigation into the ICT compo-nent of PGCE English courses. English in Education, 48(1): 63-75. https://doi.org/10.1111/ $\underline{\text { eie. } 12037}$ 
[14] Gimenez, T., Gimenez, T. (2014). Planning and implementing an online course as a teaching practicum activity in English language teaching, Ilha Do Desterro, 94(66): 101-132. https://doi.org/10.5007/2175-8026.2014n66p101

[15] Rozenfeld, C.C.D.F. (2011). Virtual environment in initial german teachers training as a support for language learning and teaching and reflexive teaching. Pandaemonium Ger, 43(18): 214-247.

[16] Karsenti, T., Villeneuve, S., Raby, C. (2008). The use of information and communica-tion technologies in the training of Quebec's future teachers. Educação \& Sociedade, 29(104): 865-889. https://doi.org/10.1590/S0101-73302008000300011

\section{$6 \quad$ Author}

Cui Li was born in 1982. She received her B.A. degree in English from Jilin Normal University of China, and M.A. degree in Foreign Linguistics and Applied Linguistics from Beihua University of China. Now she is a lecturer, teaching College English in Jilin Institute of Chemical Technology. Her main research field is English teaching methodology.

Article submitted 23 June 2018. Resubmitted 13 July 2018. Final acceptance 30 July 2018. Final version published as submitted by the author. 